Copyright by the Ecological Society of America (ESA). R. Q. Thomas, J. R. Kellner, D. B. Clark, and D. R. Peart

2013. Low mortality in tall tropical trees. Ecology 94:920-929. http://dx.doi.org/10.1890/12-0939.1

Ecology, 94(4), 2013, pp. 920-929

(C) 2013 by the Ecological Society of America

\title{
Low mortality in tall tropical trees
}

\author{
R. Q. Thomas, ${ }^{1,5}$ J. R. Kellner, ${ }^{2}$ D. B. Clark, ${ }^{3}$ and D. R. Peart ${ }^{4}$ \\ ${ }^{1}$ Department of Forest Resources and Environmental Conservation, Virginia Tech, Blacksburg, Virginia 24060 USA \\ ${ }^{2}$ Department of Geographical Sciences, University of Maryland, College Park, Maryland 20742 USA \\ ${ }^{3}$ Department of Biology, University of Missouri, St. Louis, Missouri 63121 USA \\ ${ }^{4}$ Department of Biology, Dartmouth College, Hanover, New Hampshire 03755 USA
}

\begin{abstract}
The dynamics of the tallest trees in tropical forests are of special interest due to their carbon content, canopy dominance, and the large canopy gaps created when they die. Known ecological mechanisms that may influence tall tree survival lead to conflicting predictions. Hydraulic stress and exposure to high winds and desiccation should increase death rates, yet the tallest trees have the greatest access to light and escape damage caused by falling boles and branches. The uncertainty in tall tree mortality rates has been difficult to address due to their low density, which makes mortality rates challenging to estimate accurately. Here, we use a combination of LiDAR remote sensing and field measurements to show that the mortality rate over 8.5 years among individuals $>40 \mathrm{~m}$ tall in 444 ha of lowland Neotropical rain forest was $1.2 \%$ per year, less than half the landscape-scale average for all canopy trees $(2.7 \%$ per year). The low mortality is likely explained by species-specific traits that decrease the mortality risk and/or ecological advantages of height that outweigh the risks. Regardless of the mechanisms, the low mortality rate has important implications for tropical forest carbon budgets, as we estimated that a single tall individual represents $2-11 \%$ of total live aboveground carbon stocks per hectare. Our findings suggest that height-specific dynamics may be surprisingly different from traditional diameter-specific dynamics, emphasizing the importance of extending ecological studies to investigate the role of tree height in forest dynamics.
\end{abstract}

Key words: carbon cycling; dynamics; LiDAR; mortality; remote sensing; tropical forest.

\section{INTRODUCTION}

Tropical forests are an important component of the global carbon cycle, and the net aboveground carbon balance of tropical forests is largely governed by the growth and death of individual trees (e.g., Lewis et al. 2009, Phillips et al. 2009, Rutishauser et al. 2010). Despite relatively low densities, large trees store substantial carbon (see Plate 1). For example, trees $\geq 70 \mathrm{~cm}$ stem diameter in a lowland rainforest in Costa Rica represented over $27 \%$ of the estimated aboveground biomass for trees $>10 \mathrm{~cm}$ diameter, but only $2 \%$ of stems (Clark and Clark 1996). Although there is much variation in diameter-height relationships (Muller-Landau et al. 2006, King and Clark 2011), very tall trees also tend to have large diameters, and thus high biomass. Consequently, the death rates of tall trees can strongly influence carbon balance. Tall tree mortality also has a major influence on the population and community dynamics of tropical forests, which are largely mediated via canopy gap formation. When very tall trees fall, they generate large gaps, due not only to their crown sizes and liana loads, but also because of the

Manuscript received 6 June 2012; revised 19 November 2012; accepted 21 November 2012. Corresponding Editor: A. W. D'Amato.

${ }^{5}$ E-mail: rqthomas@vt.edu damage they cause as they fall through the main canopy. Not surprisingly, the heights of tree crowns were the best predictors of gap size when individual trees were felled in Amazonian rain forest (Feldpausch et al. 2005). Obtaining empirical estimates of tall tree mortality rates is clearly an essential requirement for understanding and modeling the dynamics of tropical forests.

Our current understanding of relevant ecological and physiological mechanisms leads to conflicting predictions of how mortality rates should differ between the many trees in the main canopy and the relatively few that grow taller. Tall trees require a strong negative pressure gradient to lift water to canopy leaves, raising the risk of cavitation within xylem tissues (Tyree and Sperry 1989). Hydraulic limitation increases with tree height, reduces photosynthesis and growth due to stomatal closure (Ryan and Yoder 1997), and may limit tree height (Koch et al. 2004). The necessity for stomatal closure predisposes the tallest trees to desiccation stress, potentially exacerbated by their exposure to both high insolation and high winds. In addition, hurricanes cause higher mortality in taller trees (Zimmerman et al. 1994), and exposed crowns are more subject to lightning strikes. Nonetheless, there are also several positive factors associated with great height that may compensate for these negative forces. When trees emerge above the canopy, they typically grow broad, spreading 
crowns. As a result, they escape shading that may limit photosynthesis even in the main canopy, where most crowns are shaded at least partially on their sides, and are limited in areal extent by closely packed neighbors. The combination of high light intensity and great leaf area increases potential carbon gain, provided that hydraulic limitation is not so severe as to force stomatal closure. Furthermore, emergent crowns escape damage from falling boles and branches that are a significant risk in the lower strata (Clark and Clark 2001).

How does the combination of these factors affect the survival of very tall trees? Life history theory has been used (Poorter et al. 2008) to explain observations that, across species, average tree mortality rate decreases with the maximum height attained by a species in tropical forests. Specifically, Poorter et al. (2008) argue that taller species should be those adapted to low-resource environments, and to survive the long time required to reach and emerge from the canopy. Research has demonstrated life-history trade-offs among growth, reproduction, and mortality, especially comparing canopy species with subcanopy species that tend to be of smaller size, to have a smaller size at reproductive maturity, and to have higher mortality rates (Stephenson et al. 2011). However, because environmental conditions and disturbance risk change as individual trees grow taller, explanations that apply to relationships between maximum height and mortality at the species level may not apply to relationships between risk of death and height of individuals across a landscape. How mortality scales with individual tree height involves both intrinsic biological traits arising from life-history evolution, and the proximate risk associated with the environments experienced by individual trees within and above the main canopy layer (Stephenson et al. 2011). Currently, we lack a clear theoretical basis for predicting how species-specific life history traits and individually experienced environments combine to determine the relationship between tree height and mortality rate across a landscape. Apart from theoretical considerations, there are serious logistical constraints on the empirical estimation of death rates in very tall trees. These include their low density and the practical difficulties of measuring tree heights from the ground in tall closed-canopy forest.

In contrast, there are many studies relating mortality to the most easily measured index of size, tree diameter, in a range of forest types. In the temperate forests of the eastern United States, within-species mortality rates were U-shaped for all 21 species examined, with the lowest mortality rate for trees with diameters large enough to potentially occupy the canopy, but higher mortality rates for the largest-diameter trees (Lines et al. 2010). In tropical forests, the shape of this relationship appears to be highly variable across sites. MullerLandau et al. (2006) found stand-level relationships ranging from U-shaped, with lowest mortality rates at intermediate diameters, to monotonically decreasing mortality with increasing stem diameter. Other standlevel studies have found flat relationships between mortality and stem diameter (Lieberman and Lieberman 1987). There is a similar range of relationships between stem diameter and the probability of mortality at the species level (Clark and Clark 1996, King et al. 2006). This diversity of patterns, together with the scatter in height-diameter relationships, especially among larger trees (Muller-Landau et al. 2006, King and Clark 2011), provides no basis for empirical inference regarding the effects of tree height on mortality rate. Yet, we suggest that height may actually be a better predictor of mortality risk than stem diameter, particularly for large individuals. The vertical positions of tree crowns within and above the main canopy strongly influence the environments experienced by individuals. Trees within the main canopy can have a wide range of diameters yet experience similar environmental conditions. However, we are aware of only one study to date that quantified and compared mortality rates between emergent trees (based on relative crown position rather than height) and those in the main canopy layer: Herwitz et al. (2000) found higher survivorship in emergent crowns, based on repeat imagery using high-resolution stereo-photography in an Australian rainforest.

LiDAR remote sensing is a powerful tool to quantify forest structure, making it feasible to estimate canopy heights over large tropical landscapes (Clark et al. 2004). Repeat LiDAR measurements can be used to study the dynamics of forest structure and carbon cycling (Kellner et al. 2009b, 2011, Dubayah et al. 2010). Here, we use observations from LiDAR at two points in time to study the dynamics of individual trees in a manner comparable to ground-based estimates of mortality. We identified LiDAR tall trees, or LTTs (canopy objects $>40 \mathrm{~m}$ tall and exposed above the surrounding canopy) in a wellstudied old-growth tropical rain forest, and followed their fates over 8.5 years using LiDAR data. We matched a subset of these LTTs to individually tagged and monitored trees from ground samples. Next, we used the ground-based data to calibrate our LiDARbased estimates of mortality for the LTTs that were not included in the ground-based samples. Finally, we tested whether our LiDAR-based estimates of very tall tree mortality differed from ground-based estimates of mortality that included both canopy-level and taller trees.

\section{Materials and Methods}

We quantified the mortality rate between September 1997 and March 2006 for LTTs in 444 ha of old-growth tropical wet forest at La Selva Biological Station in the Atlantic lowlands of Costa Rica (See McDade et al. 1994 for more site information). We manually digitized the boundaries of canopy objects (putative crowns) for trees $>40 \mathrm{~m}$ tall using a $0.33 \mathrm{~m}$ digital canopy model (DCM) generated using airborne LiDAR (Clark et al. 2004; Appendix A). Because LTTs were identified using 
laser pulses from aircraft, they represented crown objects that are not overtopped by other trees, and are thus more exposed than trees in the adjacent main canopy layer. The $>40 \mathrm{~m}$ threshold isolated the tallest of the LTTs, those that were likely to be the individuals most exposed to light, wind, and hydraulic limitation (for context, the mean ( $\pm \mathrm{SD}$ ) canopy height in the study area was $20.3 \pm 6.9 \mathrm{~m}$ ). In total, we identified 735 LTTs in the 1997 LiDAR data. We then quantified the mean change in canopy height $(\mathrm{m})$ within the extent of each LTT over 8.5 years using an aggregated $(5 \mathrm{~m})$ DCM from 1997 and 2006 (Kellner et al. 2009a; Appendix A). We related those changes in canopy height to LTT status (living or dead) using 121 LTTs matched to mapped individual trees from ground samples (see Appendix A). These 121 individuals had a mean diameter in 1997 of at least $98.4 \mathrm{~cm}(95 \% \mathrm{CI}=52$ to $152 \mathrm{~cm}$; the mean is a minimum estimate because the most recent estimate of the diameter for 79 individuals was prior to 1997; see Appendix B for the distribution of diameter measurement years). The fates of these 121 trees were tracked annually using ground-based monitoring (Clark and Clark 2012). A tree in the field was defined as alive if any leaves were present. Trees with no leaves were judged on bark and sap characteristics before being defined as dead, with uncertain cases rechecked in subsequent annual censuses.

A logistic relationship between height change and probability of identifying a dead tree was determined using a Bayesian approach (Gibbs sampler with $1 \times 10^{6}$ iterations) to estimate the distribution of the two parameters in the logistic relationship. We used this logistic relationship and distribution of parameter estimates to propagate uncertainty in tree status to remaining LTTs whose fate was unknown but height change was known, and then aggregated across the full dataset to obtain a single, landscape-level mortality rate for LTTs. We propagated the uncertainty in the relationship between height change and mortality by iteratively sampling the posterior parameter distributions from the logistic relationship and calculating the probability that each individual died based on its height change.

We determined the landscape-scale distribution of tree mortality rates as a function of stem diameter using data from a long-term field study that used a stratified random design, based on dominant topographic and fertility gradients within old-growth forest at La Selva (Clark and Clark 2000a). Within 18 0.5-ha plots, all trees $\geq 10 \mathrm{~cm}$ stem diameter were censused annually between 1997 and 2006 as part of the CARBONO Project (methods available online). ${ }^{6}$ The distribution of the landscape-scale mortality rate for trees $>40 \mathrm{~m}$ tall was compared to the mortality rate estimate for all trees in and above the main canopy ( $\geq 30 \mathrm{~cm}$ stem diameter) and to trees across $10-\mathrm{cm}$ diameter size classes (10-20, 20-

${ }^{6}$ www.ots.ac.cr/carbonoproject
$30,30-40,40-50,50-60, \geq 60 \mathrm{~cm}$ diameter). Sample sizes for the six diameter groups were 1862, 610, 318, 199, 105, and 103 individuals, respectively. We grouped all trees $\geq 60 \mathrm{~cm}$ diameter to obtain an adequate sample for mortality estimations in this size class. Confidence intervals for the mortality rates for trees in $10-\mathrm{cm}$ diameter size classes and for all canopy trees were calculated using nonparametric bootstrapping. Individuals from those alive in 1997 were randomly selected with replacement, and a mortality rate based on the observed fate of the randomly selected individuals was calculated. The random selection was iterated 10000 times to create a distribution of mortality rate estimates. All mortality rates were annualized using the exponential equation $m=1-\exp \left(\ln \left(N_{1} / N_{0}\right) / 8.5\right)$ where $N_{1}$ and $N_{0}$ were the number of living individuals in 2006 and 1997, respectively.

Because the potential for hydraulic limitation increases with tree height, we assessed whether LTTs were more likely to be located near water features on the landscape (streams and swamps). To test this, we first calculated the distance to the nearest stream using the centroid of the polygon that defined each LTT. We then compared the mean distance to the nearest stream to a null distribution. To generate the null distribution, we randomly selected 735 pixels from the 444-ha study area (one for each tree $>40 \mathrm{~m}$ tall) and calculated the distance to the nearest stream for each pixel. We repeated this process 10000 times and calculated the mean distance to the nearest stream for each sample of 735 simulated tree locations. The null distribution therefore comprised the mean distance to the nearest stream from 10000 iterations of 735 randomly selected locations. We used the same method to assess the association between LTTs and swamps, alluvial soils, and volcanic-derived soils by calculating whether LTTs occurred more often in each environment than expected by chance. We also tested whether annual mortality rates differed for LTTs in the different soil environments (swamp, alluvial, and volcanic-derived) and as distance from stream increased (distance was binned into classes with $15 \mathrm{~m}$ per class). We estimated the mortality rate and its uncertainty in each soil environment and each distance-from-stream classification by using the LiDAR height change for each LLT in the habitat and iteratively sampling the posterior distribution of parameters describing mortality as a function of height change. Stream and soil locations were determined using information from the La Selva Geographic Information System. All analyses were conducted using the $\mathrm{R}$ program and environment for statistical computation version 2.13 (R Development Core Team 2011).

\section{RESUlts}

Across 444-ha of old-growth forest at La Selva, we identified 735 LTTs using data from airborne LiDAR acquired in 1997 (Fig. 1). These were significantly closer to streams (mean distance $37.3 \mathrm{~m}$; see Fig. 1) than 


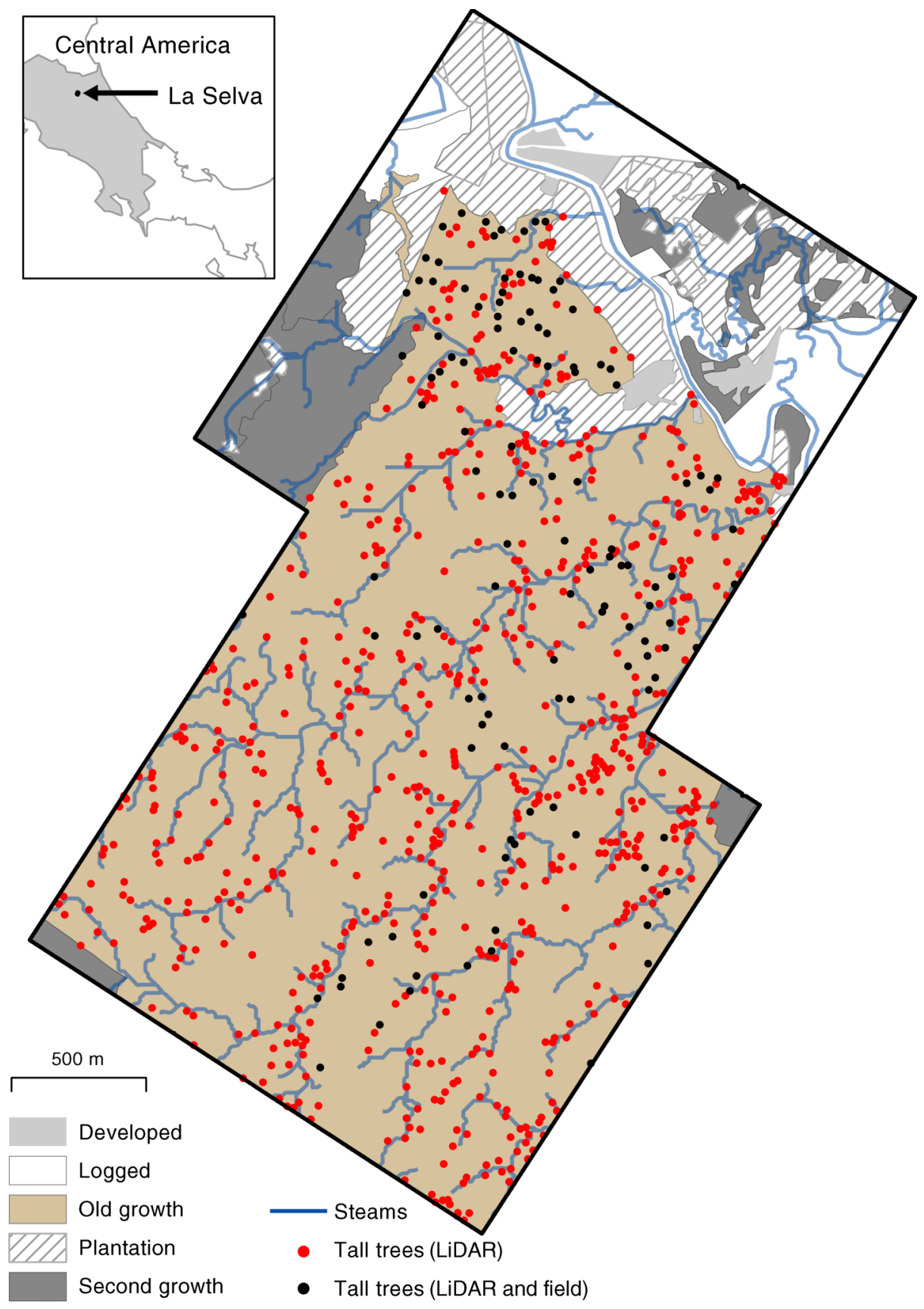

Fig. 1. La Selva, Costa Rica, showing the extent of LiDAR data coverage in 1997 and land use history. The site includes cleared or developed areas, secondary forest, and old-growth forest. Locations of trees $>40 \mathrm{~m}$ tall identified using LiDAR are in red and black; those in black were also in a long-term field study. Blue lines indicate locations of streams and rivers.

expected under the hypothesis of complete spatial randomness (mean $46.2 \mathrm{~m}, 95 \% \mathrm{CI}=43.7-48.6$ ). Similarly, the density of LTTs was significantly higher in swamps (2.72 individuals/ha) than expected by chance (1.47 individuals/ha; 95\% CI $=1.14-1.83$ ). LTT density was also higher on alluvial soils (2.60 individuals/ha) than expected by chance (1.48 individuals/ha; $95 \% \mathrm{CI}=$ 1.18-1.80). LTT density (1.23 individuals/ha) was not different than expected by chance on volcanic-derived soils (1.47 individuals/ha; $95 \% \mathrm{CI}=1.15-1.83$ ).

Of the 735 LTTs, 121 were matched to trees on the ground that had been tracked in a long-term field study, where their mortality was measured over the 8.5 -year interval between the acquisition of LiDAR data sets (Fig. 1; see also Clark and Clark 2012). The 121 trees represented seven species: Balizia elegans (31 trees), 


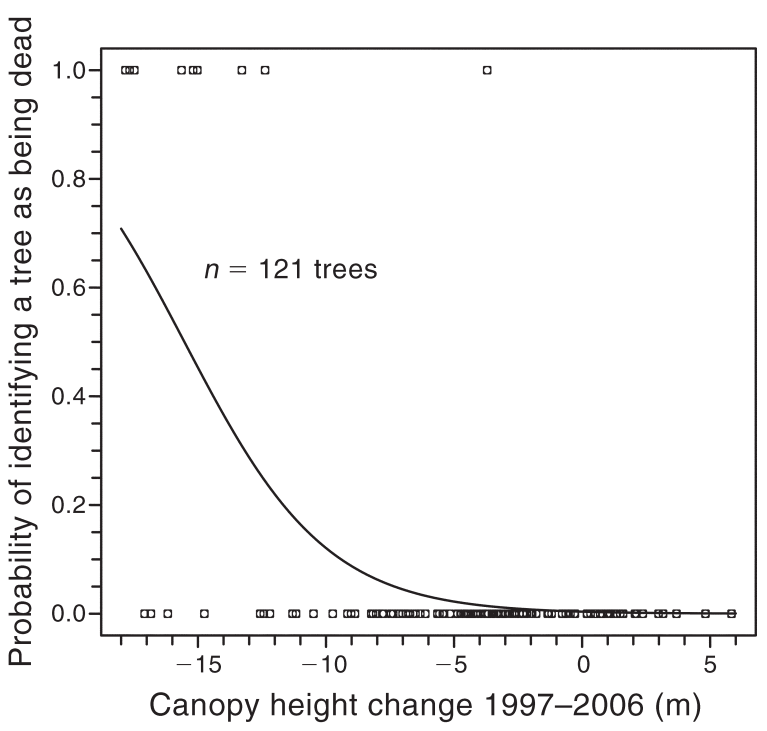

FIG. 2. The probability of identifying a tree as being dead over the 8.5-year interval in this study (1997-2006) significantly decreased with mean LiDAR-measured change in height.

Dipteryx panamensis (50), Hyeronima alchorneoides (18), Hymenolobium mesoamericanum (13), Lecythis ampla (7), Simarouba amara (1), and Minquartia guianensis (1). Over the 8.5-year study interval, 9 of the 121 trees died, corresponding to an annual mortality rate of $0.009 \mathrm{yr}^{-1}$ $(\mathrm{SD}=0.003,95 \% \mathrm{CI}=0.004-0.015)$. This mortality rate was less, but with overlapping $95 \%$ confidence intervals, than the rate for 391 individuals from the same set of species that were not matched to LTT crowns (mean = $0.014, \mathrm{SD}=0.004,95 \% \mathrm{CI}=0.010-0.018)$. The remaining 614 LTTs $>40 \mathrm{~m}$ tall in our sample were not tracked in the field, so their mortality rate in this sample cannot be estimated from the ground. Instead, their mortality could only be estimated using changes in canopy height from airborne LiDAR data.

Tree death and height change, as measured using LiDAR between 1997 and 2006, were significantly related. For the 121 trees that were tracked in the field, the mean change in canopy height between years was $-4.74 \mathrm{~m}$, and ranged from -17.83 to $5.84 \mathrm{~m}$. As the mean height change within the area of each tree crown increased (i.e., less height loss or more height gain), the probability of identifying a dead tree (based on field data) decreased significantly (logistic regression, $b_{0}=$ $5.575, \mathrm{SD}=1.03,95 \% \mathrm{CI}=3.85-7.87 ; b_{1}=0.359, \mathrm{SD}=$ $0.08,95 \% \mathrm{CI}=0.21-0.54$; Fig. 2). We applied this relationship to mean height changes in the LTTs to estimate the mortality rate among 614 LTTs whose fates were unknown, and to calculate a combined mortality rate for all LTTs in our sample. See Fig. 3 for illustrative examples of LTTs that survived and died within the 121 trees that were tracked in the field. Fig. 3 also shows LTTs whose fate was unknown but whose probability of mortality, based on height change, was calculated.
The 614 LTTs $>40 \mathrm{~m}$ tall that were not tracked in the field had a similar mortality rate to the 121 trees $>40 \mathrm{~m}$ tall that were field monitored. For the 614 LTTs not tracked in the field, the mean change in canopy height was $-5.27 \mathrm{~m}$, and ranged from -27.5 to $8.8 \mathrm{~m}$. Propagation of uncertainty in the relationship between observed height changes and the probability of mortality indicates an annual mortality rate for the 614 LTTs of $0.012 \mathrm{yr}^{-1}(\mathrm{SD}=0.003,95 \% \mathrm{CI}=0.006-0.018)$, with a $95 \%$ CI that includes the rate estimated for 121 trees in the ground-based sample $\left(0.009 \mathrm{yr}^{-1}\right)$. Combining the number of known death events from 121 trees with predicted mortality events for the remaining 614 LTTs indicates an annual mortality rate across all $735 \mathrm{LTTs}$ of $0.012 \mathrm{yr}^{-1}(\mathrm{SD}=0.002,95 \% \mathrm{CI}=0.007-0.017$; Fig. 4 [note that the mean rate for the 735 trees did not differ from the rate for the 614 LTTs when rounded to three decimal places]). Across the landscape, mortality rates for the 735 LTT did not differ among swamps, alluvial soils, and volcanic-derived soils nor with distance from a stream (Appendix C).

The annual mortality rate for the 735 LTTs was less than the ground-based mortality rate for trees $>30 \mathrm{~cm}$ stem diameter (including very tall trees) and did not have overlapping 95\% confidence intervals (groundbased data from 180.5 -ha plots; $n=725$ trees, mean mortality rate $=0.027$, bootstrapped $95 \%$ CI $=0.023-$ 0.031; Fig. 4). The ground-based annual mortality rate did not vary with diameter for the $10-\mathrm{cm}$ diameter classes $(10-20,20-30,30-40,40-50,50-60$, and $>60$ $\mathrm{cm}$ diameter); $95 \%$ confidence intervals overlapped for all diameter classes (Fig. 4). All diameter size classes had a higher mortality rate than the 735 LTTs (Fig. 4).

\section{Discussion}

Trees $>40 \mathrm{~m}$ tall are experiencing a mortality rate that is less than half the rate of mortality in the canopy as a whole. This finding is based on analyses of 121 trees $>40$ $\mathrm{m}$ tall that were tracked over 8.5 years, and to an additional 614 individuals in 444 ha of lowland Neotropical rain forest using data from airborne LiDAR. We have demonstrated that tall trees distinguished using LiDAR data can be matched to individuals on the ground, and that known mortality events produce clear changes that are detectable using LiDAR data. Our findings are consistent with the relatively low mortality rates of emergent trees in an Australian rain forest, identified with stereo-photography (Herwitz et al. 2000). However, our finding was surprising because evidence to date at the site (Fig. 4; see also Lieberman and Lieberman 1987, Clark and Clark 1996) indicated that mortality rates do not decrease with diameter (Fig. 4). Therefore, defining tree size using height, rather than diameter, exposed previously undetected size-based heterogeneity in mortality (Fig. 4). The low mortality in tall trees is likely due to a combination of two reasons: species-specific traits that increase longevity throughout all life stages, and the ecological advantages of growing 

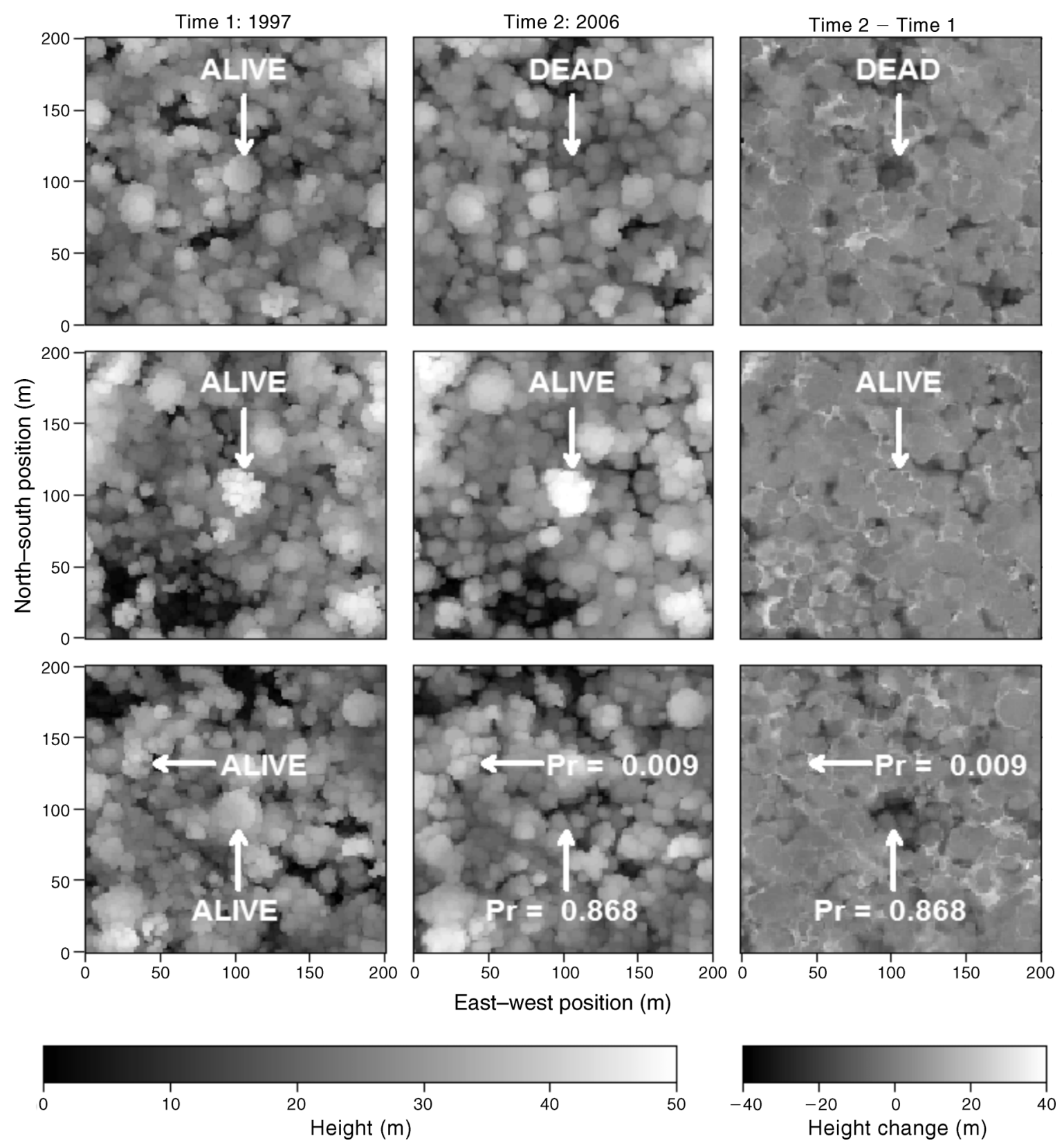

FIG. 3. Landscape-scale mortality of tall tropical trees was quantified using LiDAR. Panels show examples of trees whose fates were known from field data (top and middle rows) and whose fate was unknown (bottom row). The first and second columns are canopy height data measured using LiDAR in 1997 and 2006, respectively, and the third column is the change in canopy height from 1997 to 2006. For the two trees in the lower panels, mean height change within the delineated crown area (lower-right panel) and the relationship in Fig. 2 were used to predict the probability (Pr) that the tree identified using LiDAR in 1997 (lower-left panel) was dead in 2006 (lower-middle panel).

to be one of the tallest individuals in the forest. We explore these two hypotheses in this section.

The low death rate of very tall trees has clear and important implications for canopy gap dynamics. The tallest individuals create large canopy gaps (Feldpausch et al. 2005), especially when tree fall leads to the loss of neighboring smaller crowns via direct mechanical damage or liana connections, and by the loss of liana crowns themselves. Our results imply that the creation rate of very large gaps by the death of a single tree should be quite low, due to the combination of the relative rarity of very tall trees in space and their low death rates. The low rate of large gap formation by individual trees is supported by observations that large gaps are relatively infrequent across the landscape at $\mathrm{La}$ Selva (Kellner et al. 2009b). 


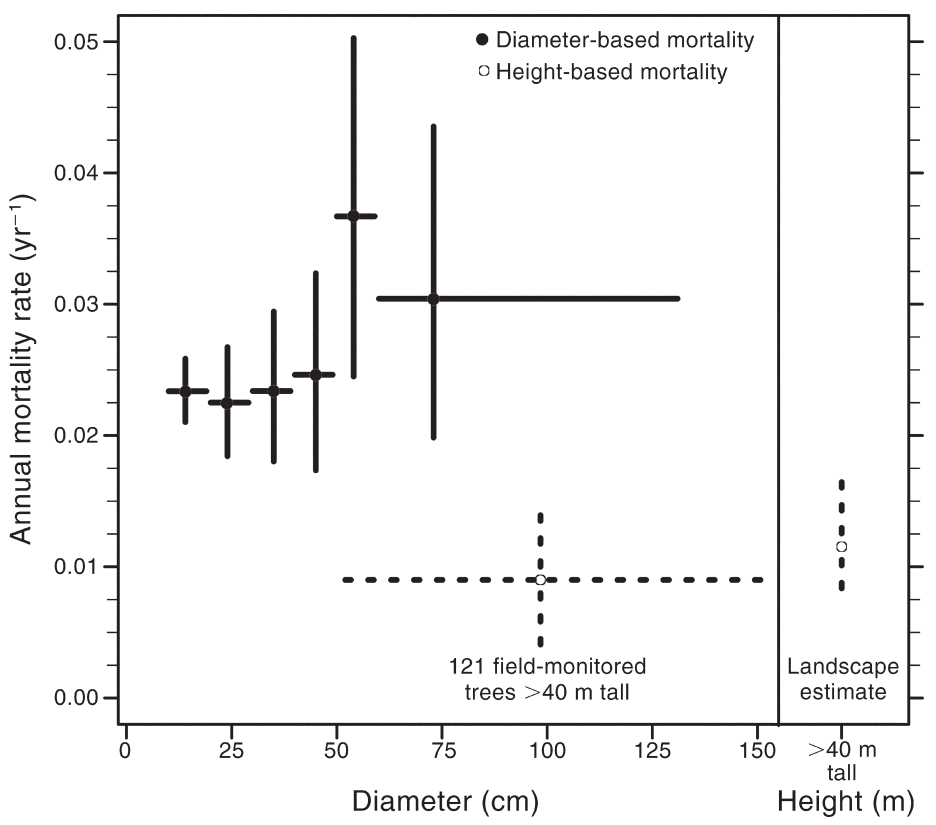

FIG. 4. Mean annual mortality rate at La Selva Biological Station, Costa Rica for the LiDAR sample of trees $>40 \mathrm{~m}$ tall (open circles) was significantly less than the mortality rate of canopy trees from all diameter-based size classes $(>10 \mathrm{~cm}$ diameter, solid circles) measured in the field study. Vertical bars are $95 \%$ confidence intervals, and horizontal bars show the range of diameters included in each mortality estimate. The range of diameters included in the landscape sample of trees $>40 \mathrm{~m}$ tall is unknown and, therefore, not shown.

Why do trees $>40 \mathrm{~m}$ tall have low death rates? There are at least two broad hypotheses, which are not mutually exclusive. First, the species that most frequently grow very tall may have inherently low death rates relative to species that are typically limited to the main canopy (species-specific hypothesis). The inherently low death rates may be associated with life-history traits, such as high wood density (Poorter et al. 2008) or delayed reproduction (Obeso 2002), that increase survival through all life stages, thus increasing the probability of reaching tall heights. This interpretation is consistent with observations that mortality decreases with maximum height across species (Poorter et al. 2008). In fact, the LTTs likely reflect the maximum heights of the species included in the set of LTTs. At La Selva, the five species that typically achieve large diameters $(>70 \mathrm{~cm})$ do appear to have low mortality rates throughout their adult lives (Clark and Clark 1996), and, of the LiDAR-mapped trees $>40 \mathrm{~m}$ tall that were matched to tagged trees in our ground samples, 119 of $121(98 \%)$ belonged to these five species. Further, the $95 \%$ confidence interval in the mortality rate in our sample of trees $>40 \mathrm{~m}$ tall contains the mortality rate of those same five large species $\left(0.006 \mathrm{yr}^{-1}\right)$ reported in Clark and Clark (1996). Thus, overall, our results are consistent with the species-specific hypothesis.

Second, the low mortality rate in very tall trees may be due to ecological advantages that benefit individuals that attain tall heights (ecological advantages hypothesis). Potential advantages include greater carbon gain and escape from physical damage. Herwitz et al. (2000) attributed higher survival and growth in emergent canopy trees to their greater light interception and lateral canopy growth. Higher light interception likely increases carbon gain, as leaf photosynthetic rates increased through the vertical canopy profile (including emergents) for five species sampled in a Malaysian rain forest (Kenzo et al. 2006). Furthermore, growing taller than one's neighbors decreases exposure to branch falls that can increase mortality (Clark and Clark 2001).

Our results are consistent with the hypothesis that these advantages outweigh any negative effects on survival in our sample trees that may be due to hydraulic limitation, desiccation, or mechanical stress imposed by high winds. Mechanical stress from hurricanes is not a major cause of tree mortality at La Selva (Denslow and Hartshorn 1994). However, we found evidence in the distribution of LTTs across the landscape that is consistent with negative factors limiting the distribution of very tall trees. Trees $>40 \mathrm{~m}$ tall at the time of the first LiDAR collection were more likely to be found near either streams or swamps, suggesting that water availability and/or topography influences their distribution. Trees may infrequently grow $>40 \mathrm{~m}$ tall on ridges or steep slopes at La Selva where desiccation may be greater, soils less stable, and wind speeds higher. Water stress is known to strongly influence mortality in other tropical forests, e.g., following the 2005 Amazonian drought (Phillips et al. 2009) and in drought experiments (Nepstad et al. 2007). While we did find evidence that 


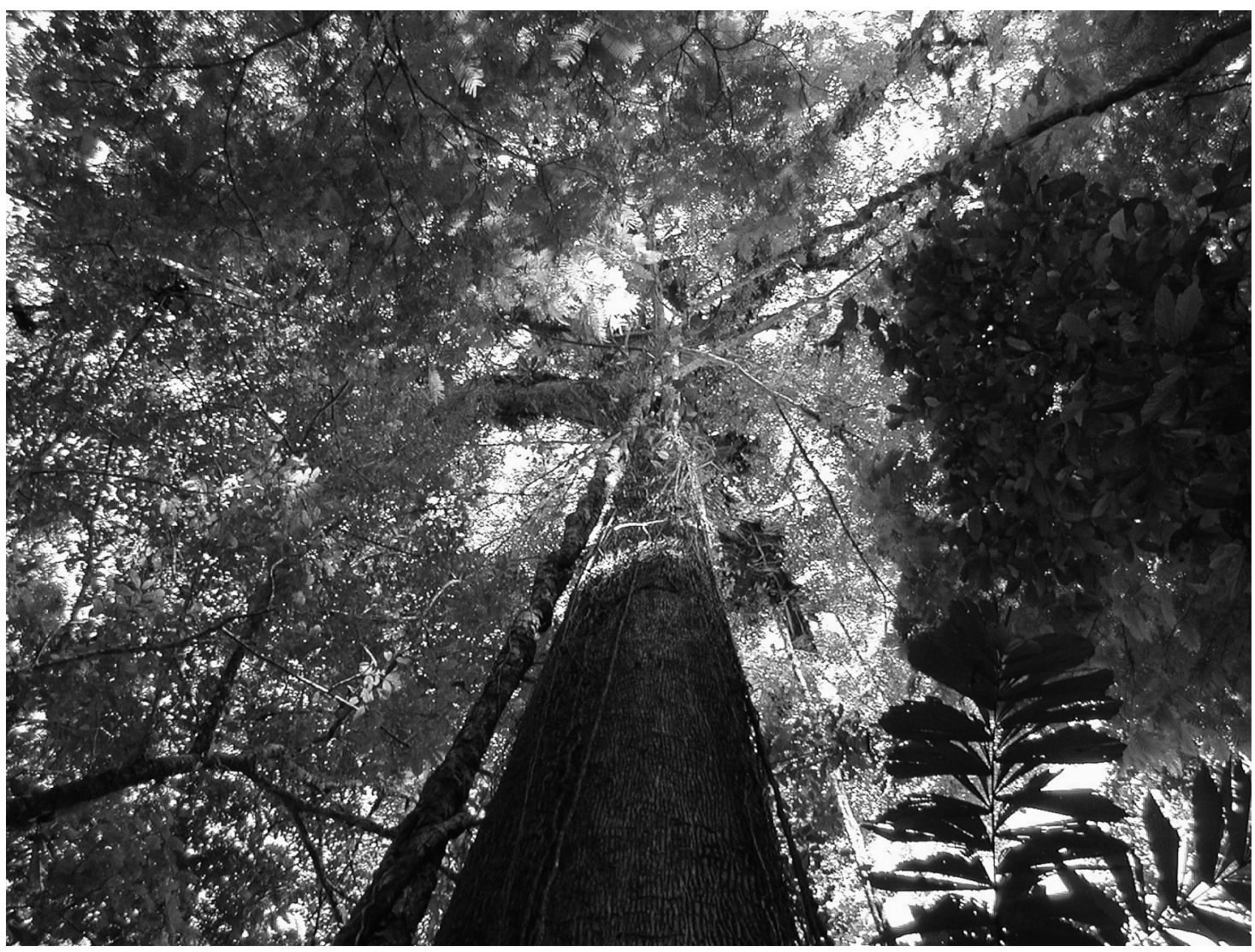

Plate 1. Very large tropical trees are relatively rare but store a significant portion of total aboveground carbon and are important in local disturbance regimes. The Lecythis ampla (Lecythidaceae) pictured here is a common emergent in old-growth forest at the La Selva Biological Station in Costa Rica, where it regularly surpasses $1 \mathrm{~m}$ in trunk diameter and $40 \mathrm{~m}$ in height. Photo credit: D. B. Clark.

distributional patterns were related to streams and swamps, we found no differences in mortality rates for LTTs in swamps vs. outside swamps. Likewise, tall trees near streams did not have lower mortality rates than individuals farther from streams. However, the uncertainty in the LiDAR-based estimates of mortality reduces our power to detect subtle patterns, and thus we cannot definitively rule out local environmental controls on mortality.

The species-specific and the ecological-advantages hypotheses are not mutually exclusive, because individuals of tree species with inherently low mortality rates could still experience a lower mortality risk as they achieve very tall heights. The relative strengths of the effects represented by these two hypotheses could be tested by quantifying (across species) differences in mortality rate between individuals at a range of tree heights. With such data, one could test not only for the main effects of height (or relative height) and species, but also for their interaction, to determine whether the effects of relative height on mortality are dependent on species identity. Most tropical tree species, including the very tall species, exist at densities of $\leq 1$ individual $\geq 10$ $\mathrm{cm}$ diameter per hectare. Our results show it is now feasible to obtain the sample sizes necessary for testing these hypotheses by mapping tree heights over mesoscale landscapes, followed by groundwork to determine the species identities of the identified and geolocated very tall trees. In lieu of species-specific data describing how mortality rates vary with height, available evidence on mortality rates from a group of species at La Selva is consistent with species-specific hypothesis. Across the five species in the long-term dataset that we used to calibrate the LTT mortality (i.e., the species including many of the tallest trees), we found that mortality rates were not statistically different for trees $\leq 40 \mathrm{~m}$ and trees $>40 \mathrm{~m}$ tall. Therefore, the species-level traits of these species may influence mortality rate more than the heights of the individuals.

The negative factors associated with very tall canopy height are likely to be most pronounced in fragmented forests and those subject to drought. The intact oldgrowth forest at La Selva in our study is likely not subject to extensive edge effects that occur in forest fragments, such as greater wind sheer, increased desiccation, and increased competition from climbing vegetation (Laurance et al. 2000); any edge effects that occur at the border with secondary and plantation 
forests (Fig. 1) were included in our estimate of low mortality in tall trees and would imply that the mortality of tall trees in the core of the old-growth forest was lower than we report. Nor is La Selva subject to severe drought (Clark et al. 2003). However, known ecological mechanisms suggest that tall tree mortality may be particularly sensitive to some of the effects of climate change, as climate change may increase drought stress in parts of the tropics (Allen et al. 2009) and may also increase hurricane intensity (Knutson et al. 2010).

Our interpretation of low mortality in tall tropical trees depends on the association of LTTs and single tree crowns. We are confident that this was the case for the $16 \%$ of the LTTs (121 of 735 ) that were matched to ground-based samples, since no crowns $>40 \mathrm{~m}$ tall were overtopped by others $>40 \mathrm{~m}$ tall. Among the other 614 LTTs, there may be cases where two or more adjacent tall trees were not separated as individuals, but rather treated in our data as a single LTT. If this error occurred, it could have altered the mortality rate estimate, depending on the tree-specific dynamics of the tall trees that were not accurately separated as individuals. Nonetheless, based on analyses of the 121 matched samples, we conclude that the potential for this error is small and our conclusions are robust.

What are the implications of low mortality in tall tropical trees for the forest carbon cycle? The low mortality rate, combined with large carbon stocks per tree, implies that substantial carbon stocks persist in a few individuals. For example, although estimating carbon stocks in tall trees is challenging due to limited allometric data (King and Clark 2011), we can approximate the carbon content in tall trees by using a diameter-carbon allometric relationship (Clark and Clark 1996), assuming that all individuals have stem diameters between 69 and $160 \mathrm{~cm}$ (the minimum and maximum diameter of trees $>40 \mathrm{~m}$ tall in King and Clark 2011), and multiplying by the observed density of 1.6 individuals/ha. Based on these assumptions, tall trees represent between $3 \%$ and $18 \%$ of live aboveground carbon stocks $>10 \mathrm{~cm}$ diameter at La Selva (total $=80.5$ $\mathrm{Mg} \mathrm{C} /$ ha; Clark and Clark 2000). The death of a single individual can be between $2 \%$ and $11 \%$ of live aboveground carbon stocks per ha, indicating that incorrectly accounting for low mortality in tall tropical trees can overestimate carbon turnover.

Our novel finding that tall tropical trees have substantially lower mortality rates than canopy trees and are more likely to be near streams and swamps was dependent on the use of LiDAR remote sensing to capture a landscape perspective of forest dynamics. The dynamics of rare but important individuals are difficult to characterize in plot-scale tropical studies: even at La Selva, a well-studied site, much of the knowledge of adult tree forest dynamics is based on only 21 ha of oldgrowth landscape (Lieberman and Lieberman 1987, Clark and Clark 2000). The success of combining LiDAR remote sensing of canopy height change with field calibration of mortality events to study individual tree dynamics suggests that widespread collection of LiDAR data may uncover previously unknown forest dynamics across the tropics and can provide a necessary baseline for detecting the influence of global change on forest dynamics.

\section{ACKNOWLEDGMENTS}

R. Q. Thomas, J. R. Kellner, and D. R. Peart conceived the research, R. Q. Thomas and J. R. Kellner designed and executed the analyses, D. B. Clark, J. R. Kellner, and R. Q. Thomas contributed to field sampling, and R. Q. Thomas, J. R. Kellner, D. R. Peart, and D. B. Clark contributed to the interpretation, analysis, and writing. We thank C. C. Carey for comments on the manuscript. We thank the Paul K. Richter and Evelyn E. Cook Richter Memorial Fund, an Andrew W. Mellon Grant to D. R. Peart, and New Hampshire NASA Space Grant for funding to R. Q. Thomas. Measurement of the 121 ground-data trees was supported by National Science Foundation TREES LTREB grant DEB-0640206 to D. A. Clark and D. B. Clark and by the Andrew W. Mellon Foundation. Research in the CARBONO plots was supported by NSF LTREB 0841872 to D. B. Clark and D. A. Clark, and by the Volcán Barva Transect TEAM Project of Conservation International, made possible with a grant from the Gordon and Betty Moore Foundation. Acquisition of LiDAR data was supported by NSF (SGER 0533575 and 0223284), NASA, the University of Maryland, TEAM, and the University of Alberta (Arturo Sánchez).

\section{Literature Cited}

Allen, C. D., et al. 2009. A global overview of drought and heat-induced tree mortality reveals emerging climate change risks for forests. Forest Ecology and Management 259:660684.

Clark, D. A., and D. B. Clark. 2001. Getting to the canopy: tree height growth in a neotropical rain forest. Ecology 82:14601472.

Clark, D. A., S. Piper, C. Keeling, and D. B. Clark. 2003. Tropical rain forest tree growth and atmospheric carbon dynamics linked to interannual temperature variation during 1984-2000. Proceedings of the National Academy of Sciences USA 100:5852-5857.

Clark, D. B., and D. A. Clark. 1996. Abundance, growth and mortality of very large trees in neotropical lowland rain forest. Forest Ecology and Management 80:235-244.

Clark, D. B., and D. A. Clark. 2000. Landscape-scale variation in forest structure and biomass in a tropical rain forest. Forest Ecology and Management 137:185-198.

Clark, D. B., and D. A. Clark. 2012. Annual tree growth, mortality, physical condition, and microsite in an old-growth tropical rain forest, 1983-2010. Ecology 93:213.

Clark, M. L., D. B. Clark, and D. A. Roberts. 2004. Small footprint lidar estimation of sub-canopy elevation and tree height in a tropical rain forest landscape. Remote Sensing of the Environment 91:68-89.

Denslow, J., and G. S. Hartshorn. 1994. Tree fall gap environments and forest dynamic processes. Pages 120-127 in L. A. McDade, editor. La Selva: ecology and natural history of a Neotropical rain forest. University of Chicago Press, Chicago, Illinois, USA.

Dubayah, R. O., S. L. Sheldon, D. B. Clark, M. A. Hofton, J. B. Blair, G. C. Hurtt, and R. L. Chazdon. 2010. Estimation of tropical forest height and biomass dynamics using Lidar remote sensing. Journal of Geophysical Research 115:G00E09.

Feldpausch, T. R., S. Jirka, C. A. M. Passos, F. Jasper, and S. J. Riha. 2005. When big trees fall: damage and carbon 
export by reduced impact logging in southern Amazonia. Forest Ecology and Management 219:199-215.

Herwitz, S., R. Slye, and S. Turton. 2000. Long-term survivorship and crown area dynamics of tropical rain forest canopy trees. Ecology 81:585-597.

Kellner, J. R., G. P. Asner, P. M. Vitousek, M. A. Tweiten, S. Hotchkiss, and O. A. Chadwick. 2011. Dependence of forest structure and dynamics on substrate age and ecosystem development. Ecosystems 14:1156-1167.

Kellner, J., D. Clark, and M. Hofton. 2009a. Canopy height and ground elevation in a mixed-land-use lowland Neotropical rain forest landscape. Ecology 90:3274.

Kellner, J. R., D. B. Clark, and S. P. Hubbell. 2009b. Pervasive canopy dynamics produce short-term stability in a tropical rain forest landscape. Ecology Letters 12:155-164.

Kenzo, T., T. Ichie, Y. Watanabe, R. Yoneda, I. Ninomiya, and T. Koike. 2006. Changes in photosynthesis and leaf characteristics with tree height in five dipterocarp species in a tropical rain forest. Tree Physiology 26:865-873.

King, D. A., and D. A. Clark. 2011. Allometry of emergent tree species from saplings to above-canopy adults in a Costa Rican rain forest. Journal of Tropical Ecology 27:573-579.

King, D., S. J. Davies, and N. Noor. 2006. Growth and mortality are related to adult tree size in a Malaysian mixed dipterocarp forest. Forest Ecology and Management 223:152-158.

Knutson, T. R., J. L. McBride, J. Chan, K. Emanuel, and G. C. Holland, C. Landsea, I. Held, J. P. Kossin, A. K. Srivastava, and M. Sugi. 2010. Tropical cyclones and climate change. Nature Geoscience 3:157-163.

Koch, G., S. Sillett, G. Jennings, and S. Davis. 2004. The limits to tree height. Nature 428:851-854.

Laurance, W., P. Delamonica, S. Laurance, H. Vasconcelos, and T. Lovejoy. 2000. Conservation-rainforest fragmentation kills big trees. Nature 404:836-836.

Lewis, S. L., et al. 2009. Increasing carbon storage in intact African tropical forests. Nature 457:1003-1006.

Lieberman, D., and M. Lieberman. 1987. Forest tree growth and dynamics at La Selva, Costa Rica (1969-1982). Journal of Tropical Ecology 3:347-358.

Lines, E. R., D. A. Coomes, and D. W. Purves. 2010. Influences of forest structure, climate and species composition on tree mortality across the eastern US. PLoS ONE 5:e13212.
McDade, L., K. Bawa, H. Hespenheide, and G. Hartshorn, editors. 1994. La Selva: ecology and natural history of a Neotropical rain forest. University of Chicago Press, Chicago, Illinois, USA.

Muller-Landau, H. C., et al. 2006. Testing metabolic ecology theory for allometric scaling of tree size, growth and mortality in tropical forests. Ecology Letters 9:575-588.

Nepstad, D. C., I. M. Tohver, D. Ray, P. Moutinho, and G. Cardinot. 2007. Mortality of large trees and lianas following experimental drought in an amazon forest. Ecology 88:22592269.

Obeso, J. R. 2002. The costs of reproduction in plants. New Phytologist 155:321-348.

Phillips, O. L., et al. 2009. Drought sensitivity of the Amazon rainforest. Science 323:1344-1347.

Poorter, L., et al. 2008. Are functional traits good predictors of demographic rates? Evidence from five Neotropical forests. Ecology 89:1908-1920.

R Development Core Team. 2011. R: A language and environment for statistical computing. R Foundation for Statistical Computing, Vienna, Austria. http://www. R-project.org/

Rutishauser, E., F. Wagner, B. Herault, E.-A. Nicolini, and L. Blanc. 2010. Contrasting above-ground biomass balance in a Neotropical rain forest. Journal of Vegetation Science 21:672-682.

Ryan, M., and B. Yoder. 1997. Hydraulic limits to tree height and tree growth. BioScience 47:235-242.

Stephenson, N. L., P. J. van Mantgem, A. G. Bunn, H. Bruner, M. E. Harmon, K. B. O'Connell, D. L. Urban, and J. F. Franklin. 2011. Causes and implications of the correlation between forest productivity and tree mortality rates. Ecological Monographs 81:527-555.

Tyree, M., and J. Sperry. 1989. Vulnerability of xylem to cavitation and embolism. Annual Review of Plant Physiology and Plant Molecular Biology 40:19-38.

Zimmerman, J. K., E. M. Everham, R. B. Waide, D. J. Lodge, C. M. Taylor, and N. V. L. Brokaw. 1994. Responses of tree species to hurricane winds in subtropical wet forest in Puerto Rico-implications for tropical tree life-histories. Journal of Ecology 82:911-922.

\section{Supplemental Material}

Appendix A

Methods for delineating individual tree crowns and calculating height change (Ecological Archives E094-078-A1).

Appendix B

A histogram with the year of the last diameter measurement for the 121 LiDAR tall trees (LTTs) tracked in the field (Ecological Archives E094-078-A2).

Appendix C

A table describing the annual mean mortality across different habitats at La Selva (Ecological Archives E094-078-A3). 